\title{
ARMC5 mutation in a Portuguese family with primary bilateral macronodular adrenal hyperplasia (PBMAH)
}

\author{
Teresa Rego', Fernando Fonseca', Stéphanie Espiard², Karine Perlemoine², \\ Jérôme Bertherat² and Ana Agapito' \\ 'Endocrinology Department, Hospital Curry Cabral, Centro Hospitalar de Lisboa Central, Lisbon, \\ Portugal and 2Endocrinology Department, INSERM U1016, Institut Cochin, Paris Descartes University, \& \\ Center for Rare Adrenal Diseases, Hôpital Cochin, APHP-Paris, France
}

\section{Summary}

PBMAH is a rare etiology of Cushing syndrome (CS). Familial clustering suggested a genetic cause that was recently confirmed, after identification of inactivating germline mutations in armadillo repeat-containing 5 (ARMC5) gene. A 70-year-old female patient was admitted due to left femoral neck fracture in May 2014, in Orthopedics Department. During hospitalization, hypertension (HTA) and hypokalemia were diagnosed. She presented with clinical signs of hypercortisolism and was transferred to the Endocrinology ward for suspected CS. Laboratory workup revealed: ACTH $<5 \mathrm{pg} / \mathrm{mL}$; urinary free cortisol (UFC), $532 \mu \mathrm{g} / 24 \mathrm{~h}$ (normal range: 20-90); failure to suppress the low-dose dexamethasone test $(0.5 \mathrm{mg}$ every $6 \mathrm{~h}$ for $48 \mathrm{~h}$ ): cortisol $21 \mu \mathrm{g} / \mathrm{dL}$. Abdominal magnetic resonance imaging (MRI) showed enlarged nodular adrenals (right, $55 \times 54 \times 30 \mathrm{~mm}$; left, $85 \times 53 \times 35 \mathrm{~mm}$ ), and she was submitted to bilateral adrenalectomy. In 2006 , this patient's 39-year-old daughter had been treated by one of the authors. She presented with severe clinical and biological hypercortisolism. Computed tomography (CT) scan showed massively enlarged nodular adrenals with maximal axis of $15 \mathrm{~cm}$ for both. Bilateral adrenalectomy was performed. In this familial context of PBMAH, genetic study was performed. Leucocyte DNA genotyping identified in both patients the same germline heterozygous ARMC5 mutation in exon 1 C.172_173insA p.I58Nfs*45. The clinical cases herein described have an identical phenotype with severe hypercortisolism and huge adrenal glands, but different ages at the time of diagnosis. Current knowledge of inheritance of this disease, its insidious nature and the well-known deleterious effect of hypercortisolism favor genetic study to timely identify and treat these patients.

\section{Learning points:}

- PBMAH is a rare etiology of CS, characterized by functioning adrenal macronodules and variable cortisol secretion.

- The asymmetric/asynchronous involvement of only one adrenal gland can also occur, making disease diagnosis a challenge.

- Familial clustering suggests a genetic cause that was recently confirmed, after identification of inactivating germline mutations in armadillo repeat-containing 5 (ARMC5) gene.

- The insidious nature of this disease and the well-known deleterious effect of hypercortisolism favor genetic study of other family members, to diagnose and treat these patients timely.

- As ARMC5 is expressed in many organs and recent findings suggest an association of PBMAH and meningioma, a watchful follow-up is required. 


\section{Background}

Primary bilateral macronodular adrenal hyperplasia (PBMAH) was first described in 1964 by Kirschner et al. (1) and is characterized by functioning adrenal macronodules and variable cortisol secretion. It is a rare cause of hypercortisolism, representing less than $2 \%$ of all endogenous cases of CS $(2,3)$. Nevertheless, as frequently for rare diseases the exact prevalence of this disease is not known and may be indeed, underestimated, especially because of subclinical CS (4). PBMAH is an insidious disease, generally identified incidentally as bilateral adrenal hyperplasia; however, the asymmetric/asynchronous involvement of only one gland can also occur $(1,3)$. Overt CS is most frequently detected in the fifth and sixth decades of life $(1,5,6)$.

Over the last decades, several molecular mechanisms were found to be associated with PBMAH pathogenesis, even though the primary event has not been established. Melanocortin type 2 receptor (MC2R) expressed in the adrenal cortex is a G-protein-coupled receptor able to bind ACTH activating the cAMP/PKA signaling pathway. The hypothesis of activating mutations of the MC2R gene was considered, but only documented in a small number of patients $(3,5,7)$. The expression of ectopic or aberrant receptors for vasopressin, serotonin, gastric inhibitory peptide and other hormones in these patients' adrenal cells is frequently observed and has been largely investigated $(6,7,8,9)$. The stimulation of these G-protein-coupled receptors elicits cortisol production through the activation of the cAMP/PKA signaling pathway. However, whether its expression is the primary event or a secondary phenomenon to hyperproliferation and cellular differentiation is still to be ascertained $(3,6)$. Increased cortisol production in bilateral macronodular adrenal hyperplasia suppresses ACTH secretion by the adenohypophysis, justifying this disease to be labeled as ACTH-independent hypercortisolism for several years. Recent discoveries seem to be prompting to a change in paradigm. In 2003, corticotropin expression in the adrenal cortex cells of a patient with PBMAH was demonstrated (10). More recently, Louiset et al. set out to study the expression of corticotropin and its precursor pro-opiomelanocortin in tissue samples of hyperplastic adrenal cells from 30 PBMAH patients. The authors concluded that cortisol secretion in these patients seems to be regulated by ACTH produced in an autocrine/paracrine way by steroidogenic cells in the hyperplastic adrenal glands (11). For these reasons, this entity is lately better designated as primary macronodular adrenal hyperplasia instead of bilateral macronodular adrenal hyperplasia.
Knowledge of the etiology and pathogenesis of this condition has evolved over the last few years. Once considered a sporadic disease, its bilateral nature and familial occurrence suggest a likely genetic etiology $(12,13,14)$.

Recently, inactivating germline mutations in the armadillo repeat-containing 5 (ARMC5) gene, a putative tumor suppressor gene, were identified in patients with PBMAH (15). This new gene was described in patients with apparently sporadic and familial disease and was later confirmed in other studies $(3,16,17,18,19)$.

\section{Case presentation}

A 70-year-old woman with no relevant prior personal medical or surgical history was admitted to the Orthopedics Department in Hospital Curry Cabral in May 2014 due to an osteoporotic fracture of the left femoral neck after a fall at home. She underwent a total left hip replacement. During her hospital stay, high blood pressure and resistant hypokalemia were diagnosed. Physical examination revealed thin and dry skin, multiple ecchymosis, rounded and facial erythrosis, obesity (BMI $30 \mathrm{~kg} / \mathrm{m}^{2}$ ) with centripetal fat distribution and major muscle atrophy of the limbs.

\section{Familial medical history}

She had an apparently healthy 46-year-old son. Her 47-year-old daughter had been treated by one of the

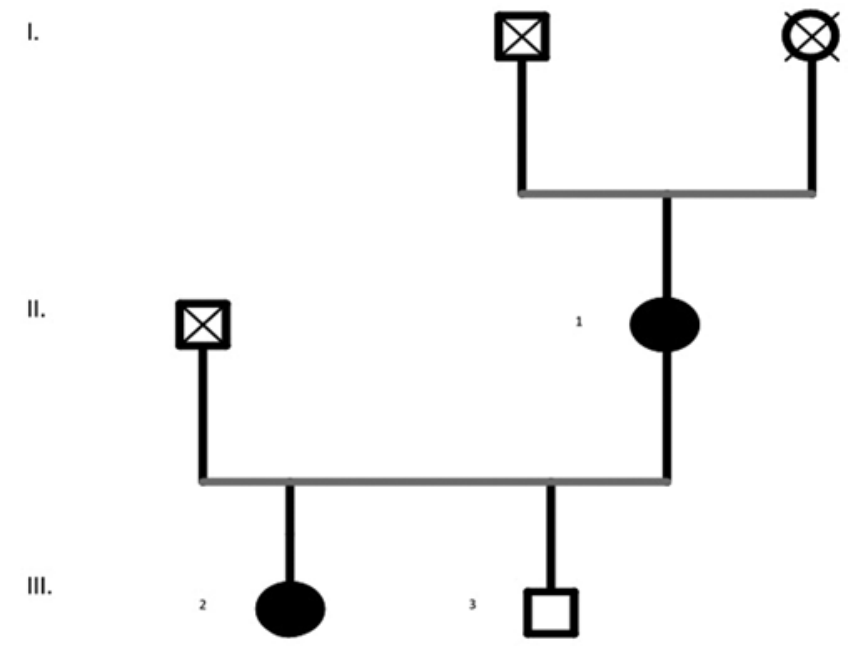

Figure 1

Family tree. 1. Proband, 2. Affected daughter, 3. Healthy son. Circles: females, squares: males, $\mathrm{X}$ : dead. 


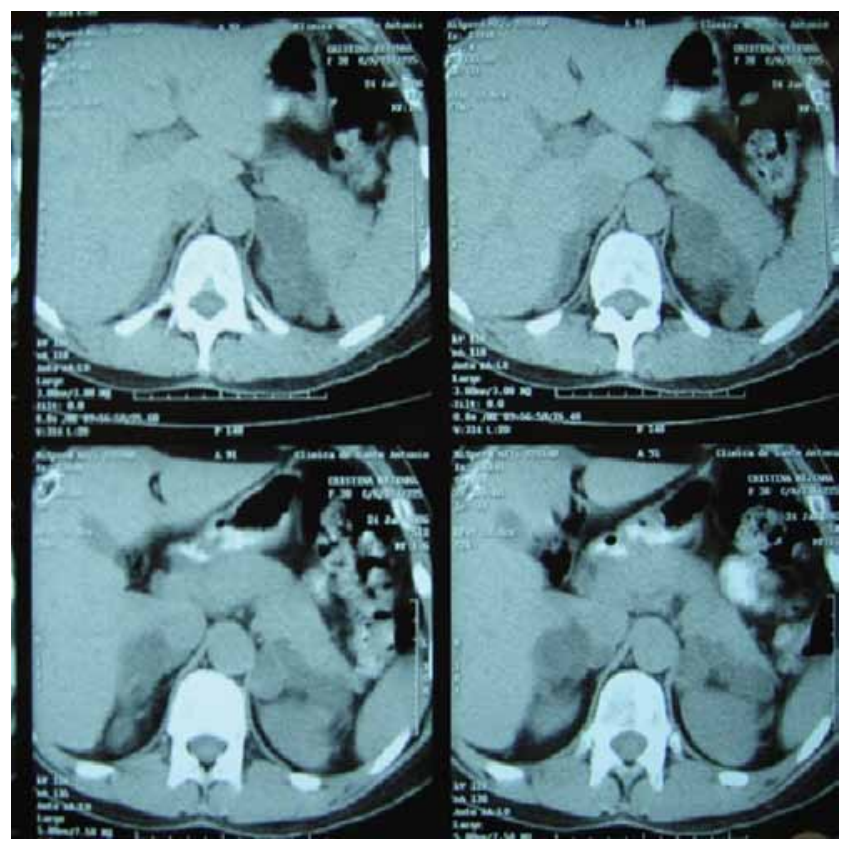

Figure 2

Daughter's abdominal CT. Bilateral enlarged adrenal glands, with lobulated contours, both with a maximum diameter of $15 \mathrm{~cm}$.

authors in 2006 for severe hypercortisolism (Fig. 1). She had uncontrolled hypertension despite being medicated with three antihypertensive agents (lisinopril $20 \mathrm{mg}$, atenolol $50 \mathrm{mg}$ and spironolactone $100 \mathrm{mg}$ ). The workup confirmed the diagnosis of Cushing's syndrome due to PBMAH, with ACTH $<5 \mathrm{pg} / \mathrm{mL}$, UFC $201 \mu \mathrm{g} / \mathrm{dL}$ (normal range 20-90), serum cortisol $16.2 \mu \mathrm{g} / \mathrm{dL}$ after standard low-dose dexamethasone suppression test and bilateral enlargement of the adrenal glands on CT, both with a maximum diameter of $15 \mathrm{~cm}$ and lobulated contour (Fig. 2). Cortisol response to various stimuli was assessed and confirmed persistent stimulation by tetracosactide, but no response to LHRH, TRH and metoclopramide (Table 1). She underwent open bilateral adrenalectomy (Fig. 3), histological diagnosis: cortical

Table 1 Daughter's cortisol response to stimulation tests with tetracosactide, LHRH (luteinizing hormone-releasing hormone), TRH (thyrotropin-releasing hormone) and metoclopramide.

\begin{tabular}{llll}
\hline \multicolumn{2}{c}{ Stimulation tests } \\
\hline & \multicolumn{1}{c}{ Serum cortisol $(\mu \mathrm{g} / \mathrm{dL})$} \\
\cline { 3 - 4 } \cline { 3 - 3 } & Basal & Peak \\
\hline Tetracosactide $250 \mu \mathrm{g}$ i.v. & & 20.3 & 66 \\
LHRH $100 \mu \mathrm{g}$ i.v. & 45 & 41 \\
TRH $200 \mu$ i.v. & 28.3 & 26.2 \\
Metoclopramide $10 \mathrm{mg}$ oral & 29.9 & 28.6 \\
\hline
\end{tabular}

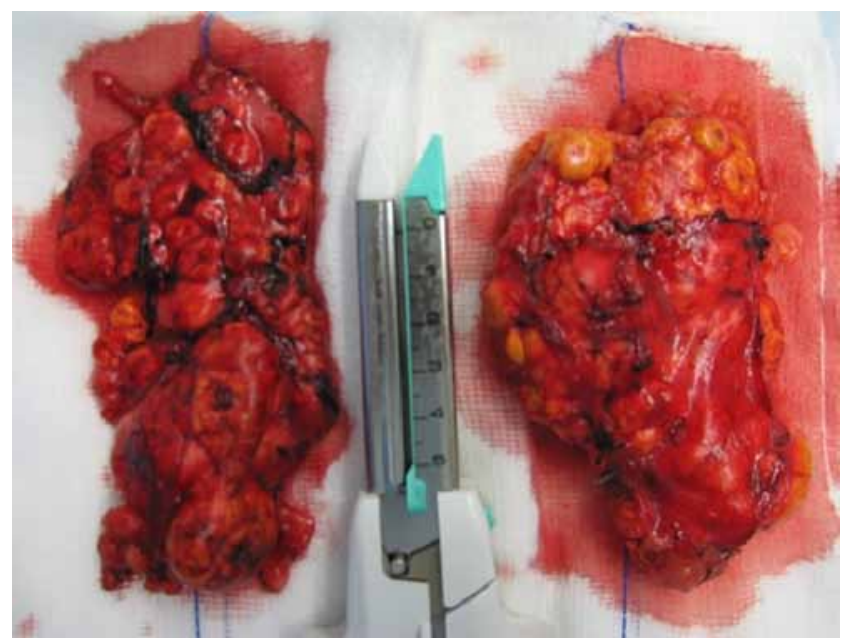

Figure 3

Daughter's lobulated right and left adrenal specimens with $68 \mathrm{~g}$ and $104 \mathrm{~g}$, respectively.

macronodular hyperplasia. She maintains follow-up in the Endocrinology Department, medicated with hydrocortisone and fludrocortisone.

\section{Investigation}

The suspicion of Cushing's syndrome motivated the patient's referral to the Endocrinology ward. The laboratory workup revealed serum morning cortisol of $21.4 \mu \mathrm{g} / \mathrm{dL}$,

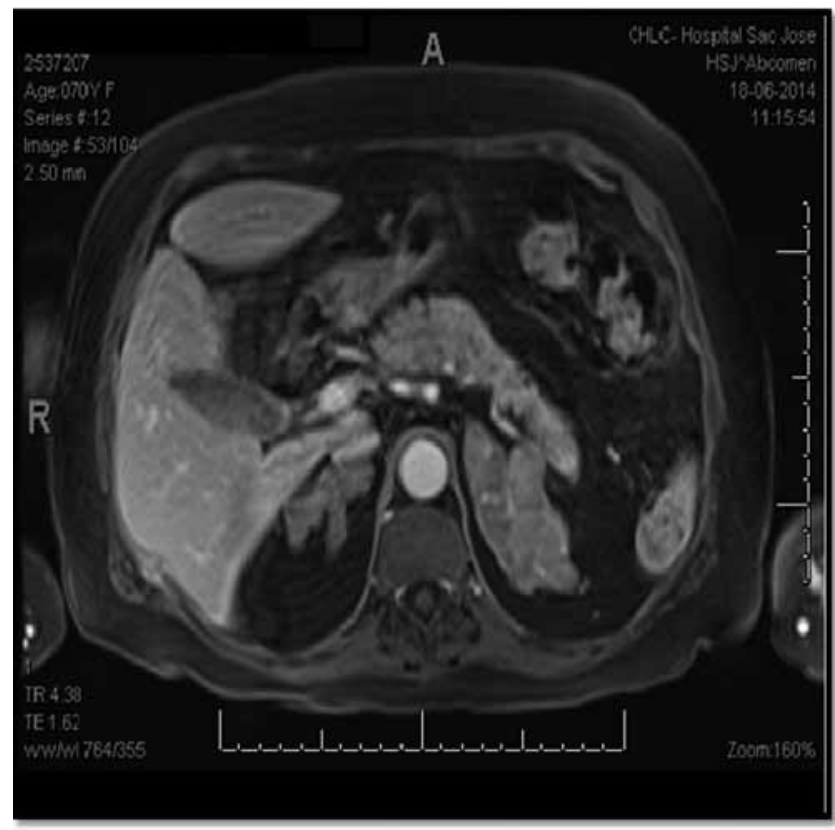

Figure 4

Proband's abdominal MRI. Bilateral enlarged adrenal glands, with lobulated contours, heterogeneous nodular structure, the right one with $55 \times 54 \times 30 \mathrm{~mm}$ and the left one with $85 \times 53 \times 39 \mathrm{~mm}$. 
ACTH $<5 \mathrm{pg} / \mathrm{mL}$, UFC of $532 \mu \mathrm{g} / 24 \mathrm{~h}$ (normal range $20-90)$, serum cortisol at $12: 00 \mathrm{~h}$ of $19.3 \mu \mathrm{g} / \mathrm{dL}$ and failure to suppress on the low-dose dexamethasone test $(0.5 \mathrm{mg}$ every $6 \mathrm{~h}$ for $48 \mathrm{~h}$ ): cortisol $21 \mu \mathrm{g} / \mathrm{dL}$, UFC $592 \mu \mathrm{g} / 24 \mathrm{~h}$. MR imaging showed bilateral enlarged adrenal glands (Fig. 4).

\section{Genetic testing}

In this context of familial Cushing syndrome, due to PBMAH, molecular study of the ARMC5 gene was performed both in the mother and daughter. ARMC5 sequencing analysis in DNA extracted from peripheral blood leucocyte showed a heterozygous mutation c.172_173insA (p.I58Nfs*45) on exon 1 in both women (Fig. 5). The study was negative for the subject's son. The older patient has no siblings, and her daughter has no progeny.

\section{Treatment}

Bilateral laparoscopic adrenalectomy (Figs 6 and 7) was performed without complications. Histopathologic examination of the surgical specimens confirmed the diagnosis of cortical nodular hyperplasia. The patient was started on replacement therapy with hydrocortisone $20 \mathrm{mg}$ and fludrocortisone $0.1 \mathrm{mg}$ per day.

\section{Outcome and follow-up}

Blood pressure normalized after surgery in both patients, maintaining endocrine follow-up for iatrogenic adrenal insufficiency. Due to recent reports of association of ARMC5 mutation with other neoplasms, such as intracranial meningioma, CT scan was performed and was normal in both patients.

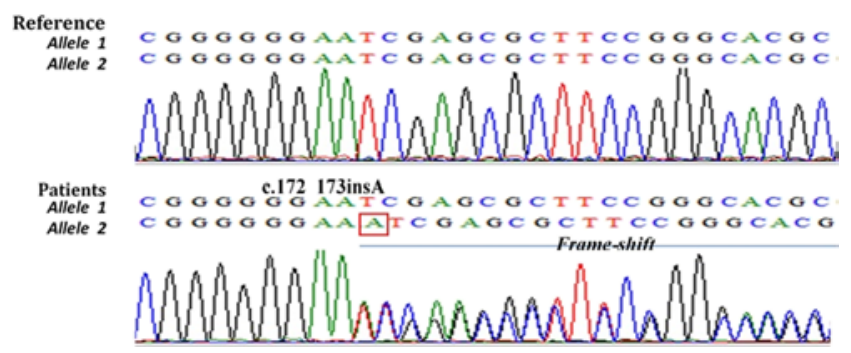

Figure 5

Chromatograph of the sequence: above, reference sequence, below, patients' sequence. The insertion of an adenine $(A)$ between the amino acid 172 and 173 according to ARMC5 CDNA (transcript NM_001105247) lead to a frame-shift and at the protein level to p.I58Nfs*45.

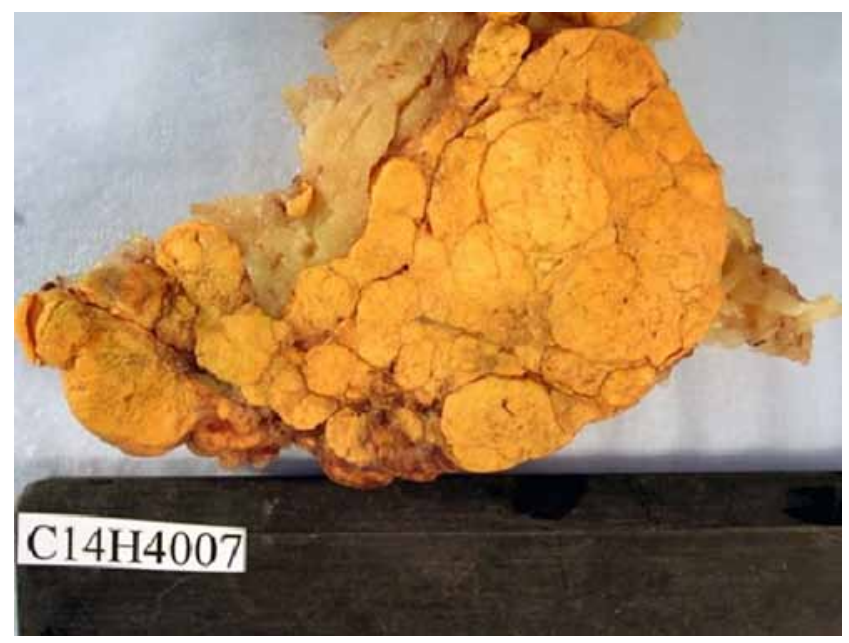

Figure 6

Right adrenalectomy specimen of the proband - macroscopic pathology showing an enlarged gland with lobulated contours - weight $62 \mathrm{~g}$.

\section{Discussion}

ARMC5 mutations were first identified in 2013 by Assié et al. in tumor samples from 18 of 33 patients (55\%) with apparently sporadic PBMAH (15). The analysis of leucocyte DNA obtained from 14 of the 18 patients detected, in all 14 patients, a germline ARMC5 mutation (15). Familial screening for this mutation was performed in 11 first-degree relatives of 7 index patients, and a germline mutation was identified in about $50 \%$ of the relatives (15). Later, mutations in ARMC5 gene were confirmed in 22-50\% of sporadic and familial PBMAH cases that were studied $(3,16,17)$. ARMC5 is located in the short arm of chromosome 16 , and its function has not

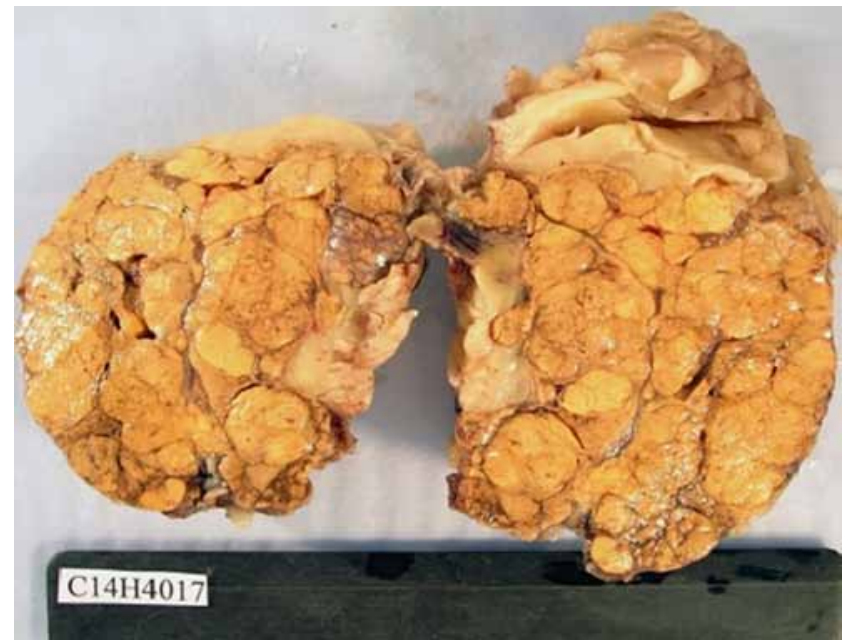

Figure 7

Left adrenalectomy specimen of the proband - macroscopic pathology showing an enlarged gland with lobulated contours - weight $151 \mathrm{~g}$. 
been established yet. It is thought to be a tumor suppressor gene as a second somatic mutational event is observed in the tumor tissue according to the Knudson's hypothesis of a tumor suppressor gene (15). The immunohistochemical analysis of adrenal samples from patients with this mutation was associated with low levels of CYP11A1 steroidogenic enzyme (15). This information supports the assumption that the inactivation of ARMC5 gene may be associated with less effective steroidogenesis through slow dedifferentiation of adrenocortical cells, which may explain the indolent natural history of this disease and the late manifestation of clinical hypercortisolism, present only after severe and irregular enlargement of the adrenal glands (15). In our 2 patients with PBMAH and ARMC5 gene mutation the weight of the adrenal glands was increased in about 10-25.

Leucocyte DNA genotyping identified in both of our patients the same germline heterozygous ARMC5 mutation in exon 1 c.172_173insA p.I58Nfs*45. This variant has already been described at the germline level by Alencar et al. and Faucz et al. and at a somatic level by Elbet et al. $(3,16,18)$. In this familial case, patients exhibited a similar phenotype, with clinical and analytical evidence of CS as well as very enlarged adrenal glands. These findings are in agreement with what was published by Faucz et al. in 2014. These authors set out to compare the clinical and analytical characteristics of 34 patients with PBMAH with or without ARMC5 gene mutation. They concluded that all patients with the pathogenic mutation presented severe clinical CS and bilateral adrenal hyperplasia (16). Therefore, we speculate that the presence of this variant can be associated with more severe disease (16). These data were supported by a large study carried out by Espiard et al. (19). Interestingly and unlike presented in our family, most of the affected patients reported by Alencar et al. exhibited subclinical CS, normal midnight salivary and 24-h UFC and normal/ partially suppressed ACTH levels (3). The first laboratory abnormality founded was the failure to suppress the low-dose dexamethasone test (3). In our case, it was not possible to perform ARMC5 analysis in tumoral DNA because no frozen tissues were available.

Although our patients have the same mutation, there was a significant difference in the age of diagnosis, which might have several explanations. Firstly, the mother had no regular medical assistance. Secondly, in PBMAH, there is a wide heterogeneity in hypercortisolism expression $(6,19)$.

The insidious nature of the disease, the asynchronous and/or asymmetrical involvement of the adrenal glands and the large spectrum of cortisol secretion raise doubts on the best therapeutic option for patients with PBMAH. Genetic study can be useful in this decision given that identification of ARMC5 mutation can predict the need for more aggressive treatment $(15,19)$. In our patients, the presence of severe clinical and analytical hypercortisolism, as well as the huge dimensions of both adrenal glands were crucial for the decision on bilateral adrenalectomy.

The ubiquitous distribution of the protein coded by the ARMC5 gene and recent reports of the association between PBMAH and meningiomas (18) raised our awareness to the need of a new attitude of follow-up for these patients.

Current knowledge on the genetic etiology of this disease and the severity of a persistent cortisol hypersecretion justify genetic screening of family members to provide early diagnosis and treatment for those affected by this condition.

\section{Declaration of interest}

The authors declare that there is no conflict of interest that could be perceived as prejudicing the impartiality of the research reported.

\section{Funding}

This research did not receive any specific grant from any funding agency in the public, commercial or not-for-profit sector.

\section{Patient consent}

We declare written informed consent has been obtained from the patients for publication of the submitted article.

\section{Author contribution statement}

Teresa $\mathrm{R}$ has written this case report during her trainee programme in the Endocrinology Department in 'Hospital Curry Cabral'. Teresa R and Fernando $\mathrm{F}$ are physicians of the older patient. Stéphanie E performed molecular analysis and provided assistance with images (chromatograph). Karine $\mathrm{P}$ performed molecular analysis and provided assistance with images (chromatograph). Jérôme $B$ performed molecular analysis and reviewed the manuscript. Ana $A$ is the clinical head of the Department of Endocrinology in 'Hospital Curry Cabral' and is the physician of the younger patient.

\section{References}

1 Kirschner MA, Powell RD Jr \& Lipsett MB 1964 Cushing's syndrome: nodular cortical hyperplasia of adrenal glands with clinical and pathological features suggesting adrenocortical tumor. Journal of Clinical Endocrinology and Metabolism 24 947-955. (doi:10.1210/jcem24-10-947) 
2 Lacroix A 2009 ACTH-independent macronodular adrenal hyperplasia. Best Practice and Research Clinical Endocrinology and Metabolism 23 245-259. (doi:10.1016/j.beem.2008.10.011)

3 Alencar GA, Lerario AM, Nishi MY, Mariani BM, Almeida MQ, Tremblay J, Hamet P, Bourdeau I, Zerbini MC, Pereira MA, et al. 2014 ARMC5 mutations are a frequent cause of primary macronodular adrenal Hyperplasia. Journal of Clinical Endocrinology and Metabolism 99 1501-1509. (doi:10.1210/jc.2013-4237)

4 Swain JM, Grant CS, Schlinkert RT, Thompson GB, vanHeerden JA, Lloyd RV \& Young WF 1998 Corticotropin-independent macronodular adrenal hyperplasia: a clinicopathologic correlation. Archives of Surgery 133 541-546. (doi:10.1001/archsurg.133.5.541)

5 De Venanzi A, Alencar GA, Bourdeau I, Fragoso MC \& Lacroix A 2014 Primary bilateral macronodular adrenal hyperplasia. Current Opinion in Endocrinology, Diabetes and Obesity 21 177-184. (doi:10.1097/ MED.0000000000000061)

6 Fragoso MC, Alencar GA, Lerario A, Bourdeau I, Almeida MQ, Mendonça BB \& Lacroix A 2015 Genetics of primary macronodular hyperplasia. Journal of Endocrinology 224 R31-R43. (doi:10.1530/JOE14-0568)

7 Swords FM, Noon LA, King PJ \& Clark AJ 2004 Constitutive activation of the human ACTH receptor resulting from a synergistic interaction between two naturally occurring missense mutations in the MC2R gene. Molecular and Cellular of Endocrinology 213 149-154. (doi:10.1016/j.mce.2003.10.052)

8 Lacroix A, Bourdeau I, Lampron A, Mazzuco TL, Tremblay J \& Hamet P 2010 Aberrant G-protein coupled receptor expression in relation to adrenocortical overfunction. Clinical Endocrinology $\mathbf{7 3}$ 1-15. (doi:10.1111/j.1365-2265.2009.03689.x)

9 Libé R, Coste J, Guignat L, Tissier F, Lefebvre H, Barrande G, Ajzenberg C, Tauveron I, Clauser E, Dousset B, et al. 2010 Aberrant cortisol regulations in bilateral macronodular adrenal hyperplasia: a frequent finding in a prospective study of 32 patients with overt or subclinical Cushing's syndrome. European Journal of Endocrinology 163 129-138. (doi:10.1530/EJE-10-0195)

10 Lefebvre H, Duparc C, Chartrel N, Jegous S, Pellerin A, Laquerriere A, Ivell R \& Vaudry H 2003 Intraadrenal adrenoccorticotropin production in a case of bilateral macronodular adrenal hyperplasia causing Cushing's syndrome. Journal of Clinical Endocrinology and Metabolism 88 3035-3042. (doi:10.1210/jc.2002-030014)

11 Louiset E, Duparc C, Young J, Renouf S, Tetsi M, Boutelet I, Libe R, Bram Z, Groussin L, Caron P, et al. 2013 Intradrenal corticotropin in bilateral macronodular adrenal hyperplasia. New England Journal of Medicine 369 2115-2125. (doi:10.1056/NEJMoa1215245)

12 Findlay JC, Sheeler LR, Engeland WC \& Aron DC 1993 Familial adrenocorticotropin-independent Cushing syndrome with bilateral macronodular adrenal hyperplasia. Journal of Clinical Endocrinology and Metabolism 76 189-191. (doi:10.1210/jcem.76.1.8380604)

13 Minami S, Sugihara H, Sato J, Tatsukuchi A, Sugisaki Y, Sasano H \& Wakabayashi I 1996 ACTH independent Cushing syndrome occurring in siblings. Clinical Endocrinology 44 483-488. (doi:10.1046/j.13652265.1996.682504.x)

14 Drougat L, Espiard S \& Bertherat J 2015 Genetics of primary bilateral macronodular adrenal hyperplasia: a model for early diagnosis of Cushing's syndrome? European Journal of Endocrinology 173 M121-M131. (doi:10.1530/EJE-15-0532)

15 Assie G, Libe R, Espiard S, Rizk-Rabin M, Guimier A, Luscap W, Barreau O, Lefevre L, Sibony M, Guinant L, et al. 2013 ARMC5 mutations in macronodular adrenal hyperplasia with Cushing's syndrome. New England Journal of Medicine 369 2105-2114. (doi:10.1056/NEJMoa1304603)

16 Faucz FR, Zilbermint M, Lodish MB, Szarek E, Trivellin G, Sinaii N, Berthon A, Libé R, Assié G, Espiard S, et al. 2014 Macronodular adrenal hyperplasia due to mutations in an armadillo repeat containing 5 (ARMC5) gene: a clinical and genetic investigation. Journal of Clinical Endocrinology and Metabolism 99 E1113-E1119. (doi:10.1210/jc.2013-4280)

17 Gagliard L, Schreider AW, Hahn CN, Feng J, Cranston T, Boon H, Hatu C, Oftedal BE, Cutfield R, Adelson DL, et al. 2014 ARMC5 mutations are common in familial bilateral macronodular adrenal hyperplasia. Journal of Clinical Endocrinology and Metabolism 99 E1784-E1792. (doi:10.1210/jc.2014-1265)

18 Elbelt U, Trovato A, Kloth M, Gentz E, Finke R, Spranger J, Galas D, Weber S, Wolf C, König K, et al. 2014 Molecular and clinical evidence for an ARMC5 tumor syndrome: concurrent inactivating germline and somatic mutations are associated with both primary macronodular adrenal hyperplasia and meningioma. Journal of Clinical Endocrinology and Metabolism 100 E119-E128. (doi:10.1210/ jc.2014-2648)

19 Espiard S, Drougat L, Libé R, Assié G, Perlemoine K, Guignat L, Barrande G, Brucker-Davis F, Doullay F, Lopez S, et al. 2015 ARMC5 mutations in a large cohort of primary macronodular adrenal hyperplasia: clinical and functional consequences. Journal of Clinical Endocrinology and Metabolism 100 E926-E935. (doi:10.1210/jc.2014-4204)
Received in final form 8 February 2017 Accepted 15 February 2017 